\title{
Peningkatan Produktivitas Melalui Penerapan 5S di IKM Kulit di Sleman, Yogyakarta
}

\author{
Suci Miranda ${ }^{1}$, Elisa Kusrini ${ }^{2)}$ \\ Teknik Industri, Universitas Islam Indonesia ${ }^{1,2)}$ \\ Jl. Kaliurang km. 14,5 Sleman, Yogyakarta 55584 Indonesia
}

Email: suci.miranda@uii.ac.id

\begin{abstract}
ABSTRAK
Industri Kecil Menengah (IKM) Kulit MARS Genuine Leather merupakan salah satu IKM di bawah pembinaan Dinas Perindustrian dan Perdagangan Kabupaten (Disperindag) Sleman, Yogyakarta. Pada tahun 2018, IKM MARS bersama dengan 10 IKM lain di Sleman dan Bantul terlibat dalam penelitian dengan Teknik Industri Universitas Islam Indonesia berkaitan dengan analisis kinerja rantai pasok menggunakan Supply Chain Operation Reference (SCOR) Model. Hasil penelitian menunjukkan bahwa IKM MARS memiliki nilai rantai pasok terendah di antara 5 IKM di wilayah Sleman. Melanjutkan hasil penelitian tersebut, perbaikan dilakukan melalui kegiatan Pengabdian Masyarakat tentang penerapan $5 S$ di IKM. Disperindag Sleman telah memberikan beberapa pelatihan mengenai penerapan 5 S bagi para pemilik IKM. Namun, pelatihan tersebut belum diterapkan langsung di tiap IKM. Oleh karena itu, kegiatan pengabdian ini bertujuan untuk memberikan pelatihan langsung penerapan $5 S$ di IKM MARS sekaligus sebagai salah satu perbaikan yang dapat dilakukan terhadap hasil penelitian analisis kinerja rantai pasok sebelumnya. Hasil pengabdian ini berupa bimbingan pelatihan langsung di IKM, video penerapan $3 S$ pertama (Seiri, Seiso, Seiton), dan formulir checklist yang dapat digunakan IKM sebagai audit internal. Pengetahuan dan ketrampilan $5 S$ yang telah diterapkan di IKM mitra diharapkan dapat membantu IKM untuk menurunkan waste (pemborosan) sekaligus meningkatkan produktivitas IKM di masa depan.
\end{abstract}

Kata kunci: IKM Kulit, Penerapan 5S, Seiri, Seiso, Seiton

\section{ABSTRACT}

Small and Medium Enterprise (SME) called MARS Genuine Leather is one of the SMEs under the guidance of the Department of Industry and Trade (Disperindag) in the Sleman region, Yogyakarta. In 2018, MARS and 10 other SMEs in Sleman and Bantul Regency have involved in research with the Department of Industrial Engineering at the Islamic University of Indonesia regarding supply chain performance analysis using the Supply Chain Operation Reference (SCOR) Model. The results showed that MARS had the lowest supply chain value among the 5 SMEs in the Sleman region. Continuing the results of the research, improvements were made through Community Service activities regarding the implementation of $5 S$ in MARS. the Department of Industry and Trade (Disperindag) of Sleman has provided several pieces of training on the implementation of $5 S$ for SME owners. However, this training has not been applied directly to each IKM. Therefore, this service activity aims to provide hands-on training on the implementation of $5 S$ at IKM MARS as well as one of the improvements that can be made to the results of previous supply chain performance analysis research. The results of this service are in the form of direct training guidance at IKM, videos of the first $3 S$ implementation (Seiri, Seiso, Seiton), and a checklist form that can be used by IKM as an internal audit. The 5S knowledge and skills that have been applied in MARS are expected to help the enterprise to reduce waste as well as increase productivity in the future.

Keywords: Application of 5S, Seiri, Seiso, Seiton, SME leather 


\section{Pendahuluan}

IKM M.A.R.S Genuine Leather merupakan salah satu IKM kulit di bawah binaan Dinas Perindustrian dan Perdagangan Kabupaten Sleman yang didirikan pada bulan Desember tahun 2017. IKM M.A..RS telah bergabung dengan Rumah Kreatif Sleman (RKS) dan mendapatkan cukup banyak pelatihan serta pendampingan langsung dari pihak Dinas guna meningkatkan produksi maupun pengembangan IKM. Namun, sebagai IKM yang baru berdiri selama kurang lebih 3 (tiga) tahun, IKM M.A.R.S masih membutuhkan pembinaan khususnya peningkatan produktivitas. Sebelumnya, IKM M.A.R.S Genuine Leather menjadi salah satu bagian dari hibah penelitian analisis pengukuran kinerja rantai pasok di IKM kulit di Yogyakarta. Terdapat 11 IKM dari Kabupaten Bantul dan Sleman dimana 6 (enam) IKM berasal dari IKM di Sleman. Berdasarkan hasil penelitian di Tabel 1, IKM M.A.R.S Genuine Leather memiliki nilai kinerja kedua terendah dibandingkan dengan IKM lainnya di Sleman yaitu berada di posisi Marginal atau di bawah rata-rata.

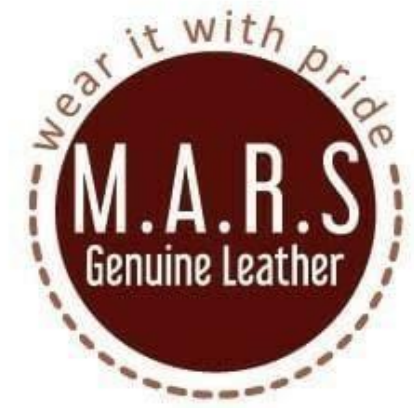

Gambar 1. Logo IKM MARS

Tabel 1. Rangkuman Nilai Kinerja Rantai Pasok

\begin{tabular}{lcccccccc}
\hline IKM & Plan & Source & Make & Deliver & Return & Enable & Nilai & KETERANGAN \\
\hline CV. Kay Nusa Bihaka & 50.56 & 61.11 & 54.01 & 98.89 & 0 & 61.88 & 54.41 & Average \\
Kingswood & 52.5 & 54.08 & 67.33 & 100 & 56.55 & 52.09 & 63.76 & Average \\
M.A.R.S Genuine Leather & 70 & 28.08 & 56.11 & 35 & 26.64 & 69.87 & 47.62 & Marginal \\
Mario Rubini & 48.89 & 60.62 & 72.37 & 84.23 & 57.21 & 44.85 & 61.36 & Average \\
Fanri Collection & 30 & 56.79 & 82.14 & 97.84 & - & 83.86 & 58.44 & Average \\
Daniela Art & 10 & 44.17 & 43.51 & 97.92 & - & 51.59 & 41.20 & Marginal \\
\hline
\end{tabular}

Sumber: Hasil Penelitian DPPM Penulis Tahun 2018

Berdasarkan Tabel 1, hasil penelitian sebelumnya didapatkan bahwa nilai rantai pasok IKM MARS masih berada pada level Marginal atau di bawah rata-rata. Sebagai Industri Kecil Menengah, para pelaku industri tidak memiliki cukup pengetahuan dalam melakukan perbaikan. Sejak berdiri di tahun 2017, IKM MARS menjadi perusahaan yang masih berada dalam tahap perkembangan dari segi proses bisnis maupun rantai pasoknya. Pada tahap tersebut, tentunya terdapat permasalahan yang dihadapi oleh perusahaan. Khususnya di masa pandemi COVID-19, perusahaan berusaha untuk menghemat biaya yang dikeluarkan termasuk biaya produksi. Beberapa outlet tas IKM MARS di beberapa hotel di Yogyakarta terpaksa harus ditutup dikarenakan physical dan social distancing yang diterapkan oleh Pemerintah. Hal ini menyebabkan menurunnya penjualan produk IKM MARS seiring dengan menurunnya jumlah pengunjung yang datang ke hotel. Selain itu, outlet IKM MARS di Turi juga ditutup sementara sebagai akibat dari pembatasan kunjungan wisatawan ke Yogyakarta. 
Untuk mempertahankan bisnis, IKM termasuk MARS harus meminimalkan biaya sambil memaksimalkan keuntungan dengan menerapkan perbaikan berkelanjutan. Metode $5 \mathrm{~S}$ adalah alat yang efektif untuk meningkatkan kinerja organisasi, apapun jenis organisasinya, ukuran, produksi atau jasanya. Akibatnya, teknik 5S akan sangat mendukung tujuan organisasi untuk mencapai peningkatan berkelanjutan dan kinerja yang lebih tinggi (Rai, 2016). Pendekatan 5S merupakan pondasi dari Total Productive Maintenance (TPM) dimana TPM fokus kepada biaya (Cost). Tujuan utama $5 \mathrm{~S}$ adalah (i) untuk mengurangi kerugian dalam bentuk limbah, (ii) meningkatkan ekonomi, (iii) mengurangi persediaan, (iv) mengurangi bahaya dan polusi, (v) meningkatkan kepuasan pelanggan internal dan eksternal, (vi) meningkatkan kualitas melalui standarisasi, (vii) meningkatkan karyawan moral, dan (viii) untuk meningkatkan partisipasi karyawan (Tayal \& Singh Kalsi, 2020). Dengan berbagai kelebihan dari pendekatan 5S, maka pendekatan ini menjadi tujuan utama dalam pengabdian masyarakat yang dilakukan. Hal ini untuk mendukung perbaikan kinerja IKM MARS sesuai dengan hasil penelitian sebelumnya di tahun 2018.

IKM MARS merupakan salah satu IKM yang dibina oleh Dinas Perindustrian dan Perdagangan (Disperindag) Kabupaten Sleman. Melalui Disperindag, para pemilik IKM mendapatkan berbagai pelatihan untuk mendukung proses bisnis mereka termasuk pelatihan 5S. Namun, secara umum pelatihan yang diberikan lebih kepada penjelasan teori tanpa praktik langsung. Sementara, memahami penerapan 5S sangat membutuhkan praktik langsung di lapangan. Menggunakan metode 5S, IKM dapat mencapai peningkatan berkelanjutan. Pemilihan IKM MARS dikarenakan nilai rantai pasok yang paling kecil diantara beberapa IKM yang diteliti pada hibah penelitian DPPM sebelumnya. Sehingga, kami ingin melalukan perbaikan di IKM MARS melalui hibah pengabdian ini. Kesuksesan implementasi 5S/5R melibatkan seluruh pihak di dalam IKM termasuk pemilik. Kegiatan 5S/5R tidak sekedar bersih-bersih, namun lebih kepada mengubah behaviour (perilaku) seluruh karyawan termasuk pemilik IKM bahwa 5S/5R menjadi budaya kerja. Melalui pengabdian masyarakat ini, IKM M.A.R.S Genuine Leather dapat menjadi IKM percontohan dalam penerapan 5S di Sleman khususnya dan Yogyakarta secara umum. Selain itu, pengabdian masyarakat ini menjadi sinergi antara Universitas, pelaku bisnis, dan masyarakat agar kebermanfaatan dari keilmuan dapat lebih menyatu.

\section{Tinjauan Pustaka}

Metode 5S Lean dikembangkan oleh Hiroyuki Hirano di Jepang pascaperang, yang terkenal digunakan oleh Toyota. Dengan mengintegrasikan prinsip-prinsip $5 \mathrm{~S}$ ke dalam kerangka kerja manufaktur mereka yang sudah terkenal yang disebut dengan Sistem Produksi Toyota (Total Production System) atau TPS, Toyota memperoleh pengakuan internasional sebagai produsen kendaraan bermotor berkualitas tinggi yang produktif. Dalam bahasa Jepang, 5S adalah: Seiri, Seiton, Seiso, Seiketsu, dan Shitsuke, yang diterjemahkan ke dalam bahasa Indonesia menjadi 5R: Ringkas, Rapi, Resik, Rawat, dan Rajin. Menurut laman Sciencedirect, penelitian terkait penerapan 5S sudah dimulai sejak tahun 2009. Penelitian ini menjelaskan bagaimana suatu Laboratorium Histology mencoba untuk menerapkan berbagai metode yang disediakan manajemen untuk dapat meningkatkan produktivitas dan mengurangi waktu penyelesaian kesalahan hingga menerapkan metode 5S (Buesa, 2009).

Ditemukan 41 publikasi berkaitan dengan penerapan 5S di laman Sciencedirect sejak tahun 2009, baik di bidang manufaktur maupun jasa. Metode 5S diterapkan untuk mendesain ulang jalan napas pada ruang operasi rumah sakit dan ruang penyimpanan peralatan (Weigel, 2016). Penerapan 5S di 4 laboratorium di suatu universitas bidang teknik: Sheet Metal Forming and Cutting, Integrated Manufacturing Systems, Welding, dan Metrology selama 12 minggu menunjukkan peningkatan dalam kegiatan pembelajaran, kontrol, dan perawatan mesin dengan waktu yang berkurang, begitu juga biaya (Chourasia \& Nema, 2016). Hasil aplikasi ini juga telah memberikan ketersediaan ruangan cukup untuk peralatan di laboratorium. Pada suatu industri tekstil, penerapan 
5S memungkinkan penghematan empat jam per operator setiap minggu, yang sesuai dengan keuntungan $10 \%$ dari waktu yang tersedia per minggu dan operator, yang menunjukkan peningkatan produktivitas yang cukup besar dalam jenis industri ini (Neves et al., 2018). Sebuah studi literatur tentang penerapan $5 \mathrm{~S}$ di bidang jasa seperti di Bank dan rumah sakit di India menunjukkan bahwa efisiensi kegunaan memberikan lingkungan yang aman, mengoptimalkan penggunaan ruang, dan meningkatkan kualitas (Rai, 2016). Tujuan utamanya adalah untuk meningkatkan kualitas pelayanan dan kepuasan pelanggan.

Ada banyak penelitian yang dilakukan tentang implementasi Lean di organisasi yang lebih besar dengan fokus khusus seperti sig sigma, kaizen, just-in-time dan berbagai alat lean lainnya. Banyak dari studi tersebut menunjukkan bahwa Lean manufacturing implementasi telah mendorong organisasi dengan peningkatan yang luar biasa. Namun, implementasi di kalangan Usaha Kecil dan Menengah (UKM) atau Industri Kecil Menengah (IKM) belum begitu diteliti secara ekstensif atau bahkan diterapkan di antara perusahaan UKM/IKM. Salah satunya adalah penelitian berkaitan dengan menganalisis perubahan yang terjadi setelah penerapan $5 \mathrm{~S}$ di beberapa UKM untuk menjawab 5 hipotesis yang dibangun. Hipotesis tersebut adalah apakah setelah penerapan $5 \mathrm{~S}$ : efisiensi meningkat, ruang kerja meningkat, waktu mencari peralatan menurun, lingkungan kerja di laboratorium meningkat, dan faktor keamanan (safety) meningkat (Radzali et al., 2019). Analisis akseptabilitas dan implementasi lean manufacturing pada UKM Manufaktur India menggunakan tiga konstruk, yaitu perbaikan proses (PI), manajemen aliran (FM) dan minimisasi limbah (WM). Perusahaan yang menanggapi dikategorikan ke dalam kelompok "lean-Beginners", "In-transisi lean", dan "lean" berdasarkan fase implementasi lean mereka (Sahoo \& Yadav, 2018). Pada penelitian ini, terdapat 121 UKM yang menjadi responden.

Namun, metode ini tetap memiliki tantangan. Tantangan implementasi 5S/5R adalah membutuhkan untuk membangun budaya baru, mengubah sikap dan perilaku, menciptakan lingkungan kerja yang baik (Mehra \& Singh, 2015). Tujuan utama implementasi 5S/5R adalah untuk mencapai kualitas dan safety yang lebih baik (Jiménez et al., 2015). Beberapa kendala yang dihadapi antara lain kurangnya komitmen manajemen, kurangnya perhatian terhadap penerapan 5S, kurangnya perencanaan $5 \mathrm{~S}$ yang strategis, kurangnya komitmen karyawan, kurangnya kerjasama antar departemen, motivasi, pelatihan dan edukasi, komunikasi, kepemimpinan, keterbatasan finansial, ketidakmampuan mengubah budaya organisasi, dan tidak jelas program 5S itu sendiri. Sejalan dengan hasil ini, kurangnya komitmen dari para anggota di suatu perusahaan menjadi penyebab utama kegagalan praktik 5S (Kulkarni et al., 2016). Bagian dari komitmen para anggota adalah individualitas, norma dalam grup, komunikasi, kepaduan anggota, dan kepercayaan. Kegagalan kedua terhadap implementasi 5S adalah kurangnya komitmen dari level manajemen yang terdiri dari ketersediaan dana, pelatihan 5S, audit 5S, safety, dan infrastruktur 5S. Yang terakhir, kegagalan 5S disebabkan oleh stres dalam bekerja dimana dimensi pekerjaan, beban kerja, kontrol, dan budaya organisasi menjadi bagian dari stres tersebut. Beberapa tantangan yang dihadapi metode 5S adalah tantangan budaya, tantangan filosofi, tantangan operasional dan implementasi, dan tantangan pengukuran (Ranjith Kumar et al., 2021). Dilakukan pendekatan yang berfokus pada entropi untuk mengembangkan model kematangan (maturity model) 5S, yang dapat mengatasi tantangan dalam penerapan $5 \mathrm{~S}$ tersebut.

\section{Metodologi Pengabdian}

Faktor utama dalam kesuksesan pelaksanaan 5S/5R adalah partisipasi, komitmen, dan dukungan dari top level management. Oleh karena itu, dalam pengabdian ini kami tidak hanya memberikan pendampingan berupa pelatihan 5S/5R hanya kepada karyawan, juga kepada pemilik IKM bahwa 5S/5R merupakan tanggung jawab tiap orang dalam sistem IKM. Implementasi 5S/5R terkait 4 sumber daya: manusia, mesin, metode, dan material. S1, S2, dan S3 dilaksanakan secara disiplin dalam kurun waktu tertentu untuk mendapatkan kondisi standar atau mencapai S4-Rawat 
(Seiketsu). Apabila karyawan telah memenuhi seluruh kegiatan tersebut di atas yang dilaksanakan secara berulang-ulang, maka mereka telah memperoleh status S5-Rajin (Shitsuke) atau telah ikut serta sepenuhnya dalam pengembangan kebiasaan-kebiasaan kerja yang baik sesuai aturan yang ditetapkan.

Pengabdian masyarakat ini akan dibagi ke dalam 3 kegiatan utama: (1) Sosialisasi budaya kerja 5S/5R, kaizen (Continous Improvement), konsep 5S/5R, tahapan implementasi 5S/5R; (2) Pendampingan implementasi 3S/3R; dan (3) Evaluasi: audit pelaksanaan 3S/3R. Pada hibah pengabdian ini, kegiatan implementasi difokuskan kepada 3S pertama yaitu Seiri (Ringkas), Seiton (Rapi), dan Seiso (Resik). Kondisi standar (S4-Rawat, Seiketsu) hanya dapat tercapai jika 3S/3R pertama telah dilaksanakan secara rutin, displin, dan konsisten dalam kurun waktu tertentu misal dalam waktu 1 tahun. Setelah kondisi standar tercapai dan dapat dipertahankan secara berkelanjutan dalam suatu periode tertentu, misal 1 tahun, maka S5-Rajin (Shitsuke) akan tercapai. Oleh karena itu, dalam berbagai pelatihan penerapan $5 \mathrm{~S} / 5 \mathrm{R}$ termasuk hibah pengabdian masyarakat ini, aplikasi 3S/3R menjadi fokus utama dalam rangkaian penerapan keseluruhan 5S/5R.

Selain implementasi 3S/3R, pengabdian masyarakat ini diintegrasikan dengan penelitian Tugas Akhir mahasiswa. Penelitian dilakukan oleh 2 mahasiswa dengan judul "Desain Audit 5S untuk Pengukuran Maturity Level Implementasi 5S pada IKM" dan "Desain Sistim Informasi dari Maturity Level Implementasi 5S pada IKM". Maturity model akan membantu IKM dalam melakukan self assessment sehingga penerapan 3S/3R dapat berkelanjutan demi mencapai $\mathrm{S}$ keempat Seiketsu (Rawat), dan S kelima Shitsuke (Rajin). Video penerapan 3S/3R menjadi salah satu luaran yang dapat digunakan sebagai pengetahuan bagi IKM lain khususnya di bawah Disperindag Kabupaten Sleman.

Seperti yang telah dijelaskan sebelumnya bahwa metode 5S akan merampingkan setiap kegiatan di suatu perusahaan, tidak hanya waktu tetapi juga biaya. Hal ini sejalan dengan kondisi pandemi COVID-19 dimana IKM sebagai unit bisnis dituntut untuk dapat mempertahankan profit dan meningkatkan produktivitas sekaligus menghemat biaya. Berikut adalah penjelasan aktivitas yang akan dilaksanakan dalam pengabdian masyarakat.

Scope: Menerapkan metode 5S untuk 3S pertama (Seiri, Seiton, Seiso) di IKM MARS Genuine Leather yang dimulai dari Februari 2020 selama 6 bulan.

- Main Deliverables:

1. Penerapan 3S di IKM MARS Genuine Leather seperti pemberian label-label di tiap tempat/area dan Garis-garis pemisah di tiap tempat/area

2. Form evaluasi untuk digunakan oleh IKM

3. Form checklist untuk digunakan oleh IKM

4. Video penerapan $3 \mathrm{~S}$

- Constraints: hibah ini hanya menerapkan 3S pertama

- Assumption: semua tim bekerja sesuai dengan porsinya, IKM dapat bekerjasama dengan baik sehingga pengabdian dapat diselesaikan dalam 6 bulan tanpa ada hambatan

- Work Breakdown Structure

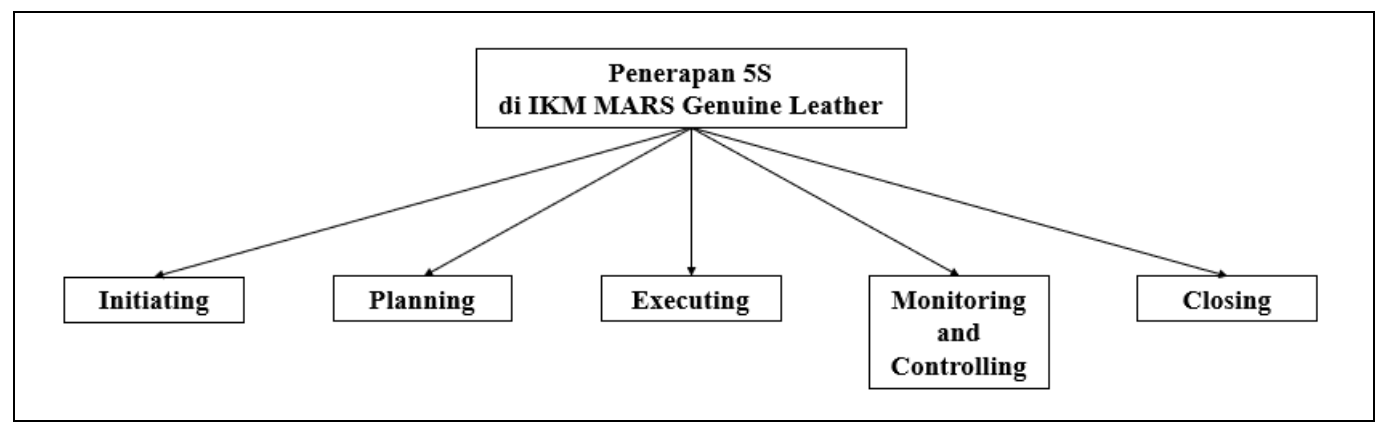

Gambar 2. Work Breakdown Structure Pengabdian Masyarakat 
1. Initiating: menentukan calon IKM mitra untuk dimasukkan ke dalam proposal pengabdian masyarakat hibah DPPM. Setelah dipilih IKM MARS Genuine Leather, tim melakukan observasi dan wawancara dengan pemilik IKM untuk menganalisis situasi dan menentukan permasalah mitra.

2. Planning: dari permasalahan mitra yang didapatkan, tim menentukan metode yang sesuai untuk menyelesaikan masalah tersebut. Kemudian, tim membuat proposal hibah pengabdian masyarakat untuk diajukan ke DPPM UII.

3. Executing: ketika proposal hibah diterima, maka tim akan menjalankan aktivitas-aktivitas yang telah dirancang terkait penerapan 3S pertama di IKM MARS Genuine Leather termasuk pembuatan video penerapan $3 \mathrm{~S}$.

4. Monitoring and controlling: melakukan audit internal oleh tim untuk mengecek konsistensi penerapan 3S di IKM.

5. Closing: diskusi terakhir terkait manfaat dan hambatan yang dialami untuk menjaga konsistensi penerapan 3S di IKM baik oleh karyawan maupun pemilik IKM, mendapatkan saran dan masukan dari IKM untuk perbaikan penerapan 3S pada IKM yang lain.

Dalam pelaksanaan program hibah pengabdian masyarakat ini, tim dibantu oleh 2 mahasiswa sebagai asisten dimana keduanya melanjutkan hibah pengabdian ini menjadi 2 penelitian Tugas Akhir seperti yang telah dijelaskan sebelumnya. Untuk pembuatan video penerapan $3 \mathrm{~S}$, tim dibantu oleh seorang mahasiswa dari Jurusan Teknik Informatika UII. Sementara, pihak IKM MARS Genuine Leather terdiri dari pemilik, Ibu Heni Sulistyawati bersama dengan suami (Bapak Satya Dona Adi R.), seorang karyawan di area packaging dan 3 orang karyawan di area produksi.

\section{Hasil dan Pembahasan}

\subsection{Penerapan 3S/3R di IKM MARS Genuine Leather}

Sebelum memulai penerapan $3 \mathrm{~S}$, pemilik dan para pekerja diberikan pemaparan materi terkait 5S dan manfaat penerapan $5 \mathrm{~S}$ beserta pengalaman tim melakukan pengabdian tentang $5 \mathrm{~S}$ di beberapa tempat lain. Pendampingan praktik ini bertujuan agar IKM MARS dan karyawan dapat memahami penerapan tiap S mulai dari memilah barang-barang, menyusun dan memberikan label, memberikan garis tiap area, dan melakukan pembersihan secara rutin. Jika $3 \mathrm{~S}$ pertama tidak dilakukan secara konsisten, maka tahap Seiketsu (Rawat) dan Shitsuke tidak akan tercapai.

Aktivitas memilah (Seiri/Ringkas) adalah memilah barang-barang kepada 3 kategori: yang tidak dipakai lagi; 2. yang masih dipakai; 3. kondisi rusak. Barang-barang yang tidak dipakai akan ditentukan apakah akan dibuang atau diberikan kepada orang lain. Barang-barang yang kondisi rusak juga harus ditentukan apakah akan dibuang atau diperbaiki untuk dipakai kembali. Sedangkan untuk barang-barang yang masih dipakai akan dibagi kepada 2 kelompok, barang-barang yang rutin dipakai (akan diletakkan di dekat karyawan) dan barang-barang yang jarang dipakai (disimpan di rak, kotak, atau gudang). Aktivitas ini dilakukan bersama dengan Bapak Dona sebagai pemilik IKM MARS bersama dengan karyawan. Gambar 3 menunjukkan kondisi sebelum diterapkan 3S dan Gambar 4 adalah aktivitas pertama dari 3S.

Setelah dilakukan pemilahan, kemudian barang-barang yang digunakan rutin akan ditempatkan dekat dengan tiap pekerja. Sementara barang-barang yang tidak terpakai akan dibuang dan yang tidak digunakan secara rutin akan dipisahkan atau ditempatkan di suatu kotak. Selanjutnya, tiap "rumah" barang-barang akan diberikan label guna memudahkan dalam pencarian barang-barang tersebut. Tempat atau rumah tiap barang harus ditentukan dan dipastikan tidak akan berubah. Gambar 5 menunjukkan kegiatan penentuan rumah tiap barang dengan memberikan garis pembatas. 


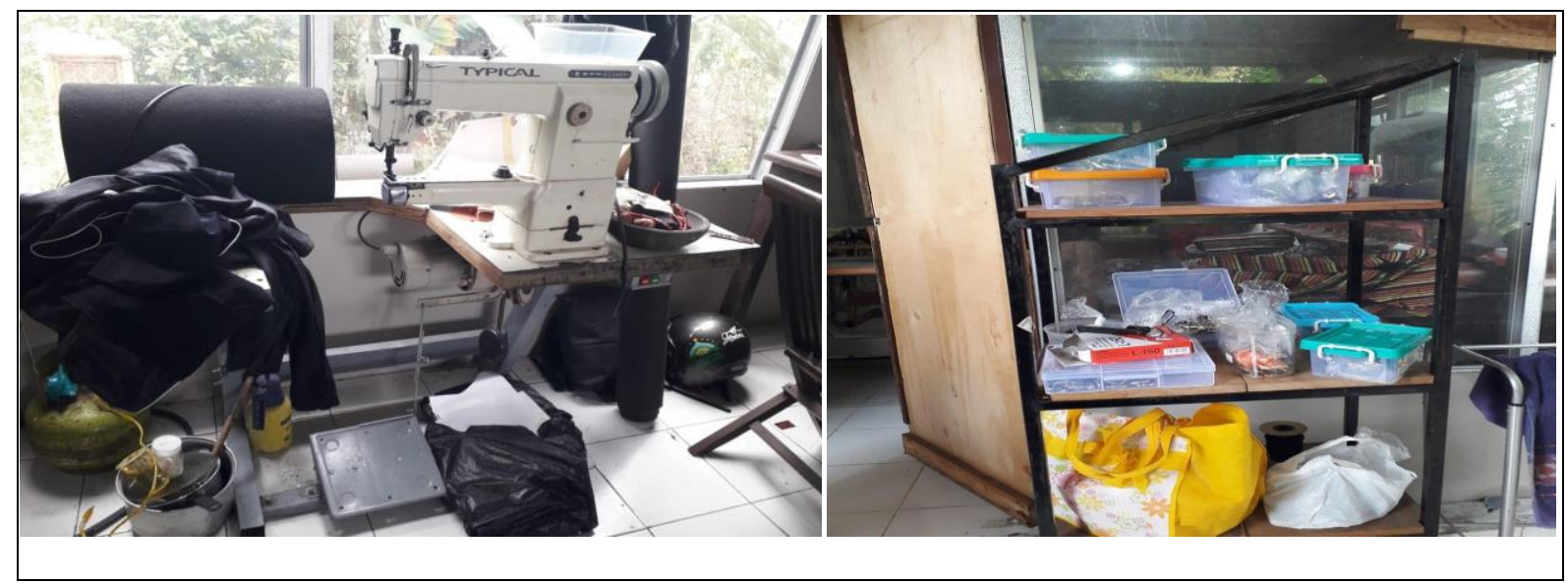

Gambar 3. Kondisi Ruang Produksi Sebelum 3S

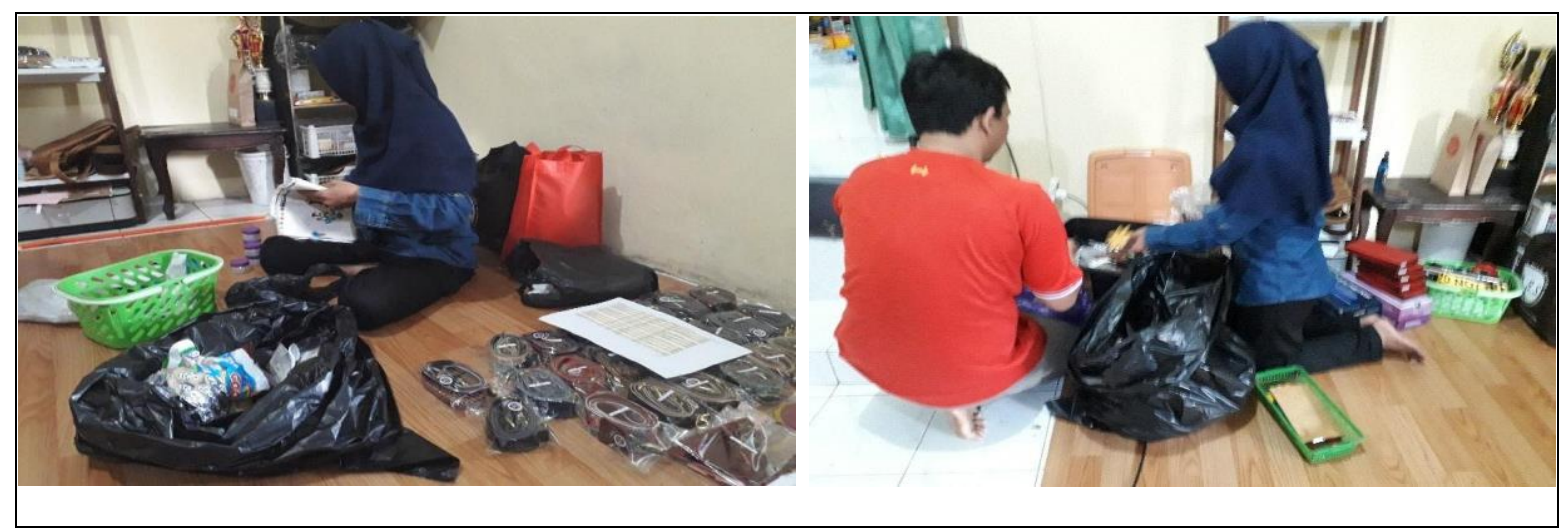

Gambar 4. Aktivitas Seiri (Ringkas)

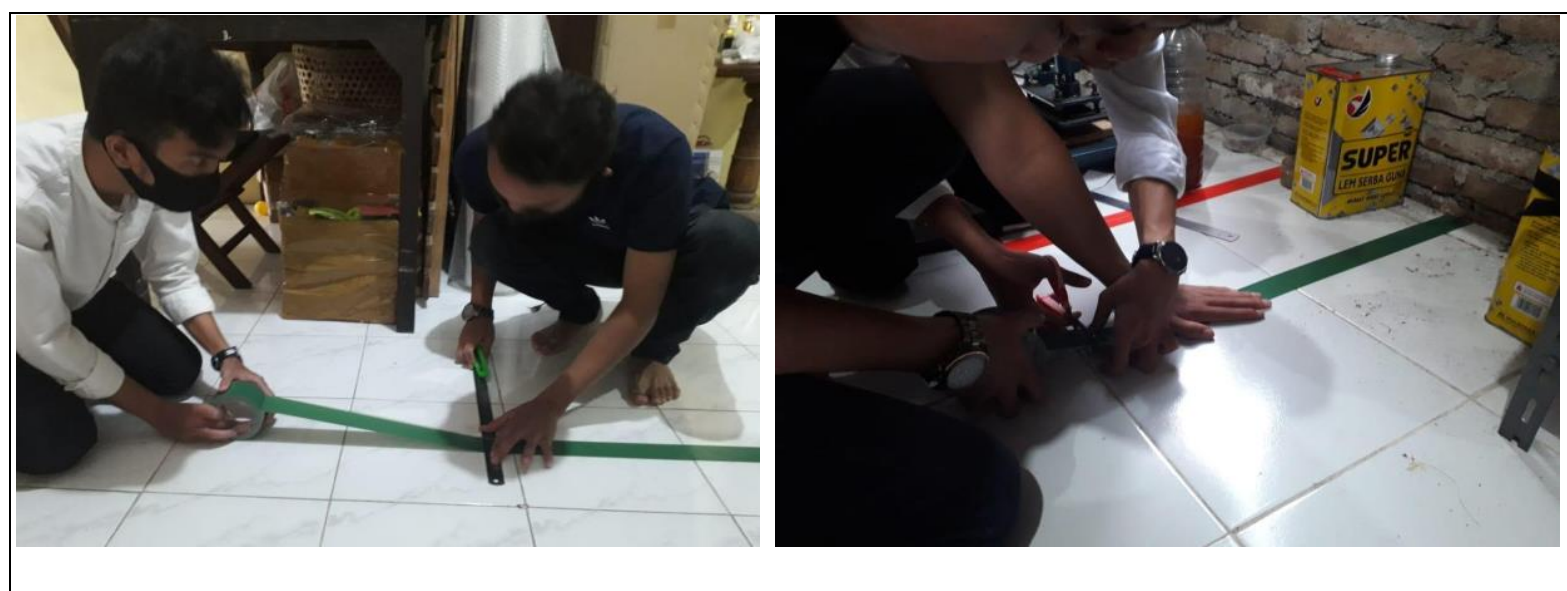

Gambar 5. Aktivitas Seiton (Rapi)

Kegiatan terakhir adalah Seiso (Resik) yaitu membersihkan semua area dan memastikan peralatan kebersihan tersedia di tiap area sehingga para pekerja dapat dengan mudah menemukan peralatan kebersihan tersebut untuk membersihkan ruang kerja. Pengaplikasian garis adalah sebagai pembatas bahwa tiap barang seperti mesin, rak, meja, berada pada tempat yang semestinya. Pada awal penerapan 3S, garis pembatas ini dibutuhkan agar semua pekerja mengetahui letak tiap barang. Seiring waktu, ketika sudah tercapai standarisasi (Seiketsu) dan keberlanjutan (Shiketsu), para pekerja sudah berada pada kondisi disiplin sehingga garis pembatas boleh dihilangkan. Hasil dari aktivitas Seiso ditunjukkan oleh Gambar 6. Pembuatan video terdiri dari aktivitas penerapan 3S 
pertama (Seiri, Seiton, Seiso) di IKM MARS, respon dari pemilik, respon dari karyawan, dan penjelasan singkat dari ketua dan anggota. Berikut adalah link video yang diunggah di laman Youtube (Gambar 7): https://youtu.be/5CZ-ouLbzgk. Video ini juga dibagikan di laman Facebook IKM MARS Genuine Leather.

Luaran tambahan dari program hibah ini adalah pelatihan penerapan 5S/5R di IKM yang diselenggarakan oleh Disperindag Kabupaten Sleman (Gambar 8). Pelatihan ini diadakan karena hibah pengabdian masyarakat hanya dapat melaksanakan program dengan 1 mitra atau IKM. Oleh karena itu, kegiatan ini diinisiasi agar IKM lain di bawah Disperindag Kabupaten Sleman juga mendapatkan pengetahuan tentang penerapan 5S/5R dimana IKM MARS Genuine Leather menjadi pilot project-nya. Kegiatan pelatihan ini dilaksanakan pada tanggal 04 Juni 2020. Sementara Form checklist (Tabel 2) menjadi panduan IKM dalam mengerjakan tiap S di masa yang akan datang.

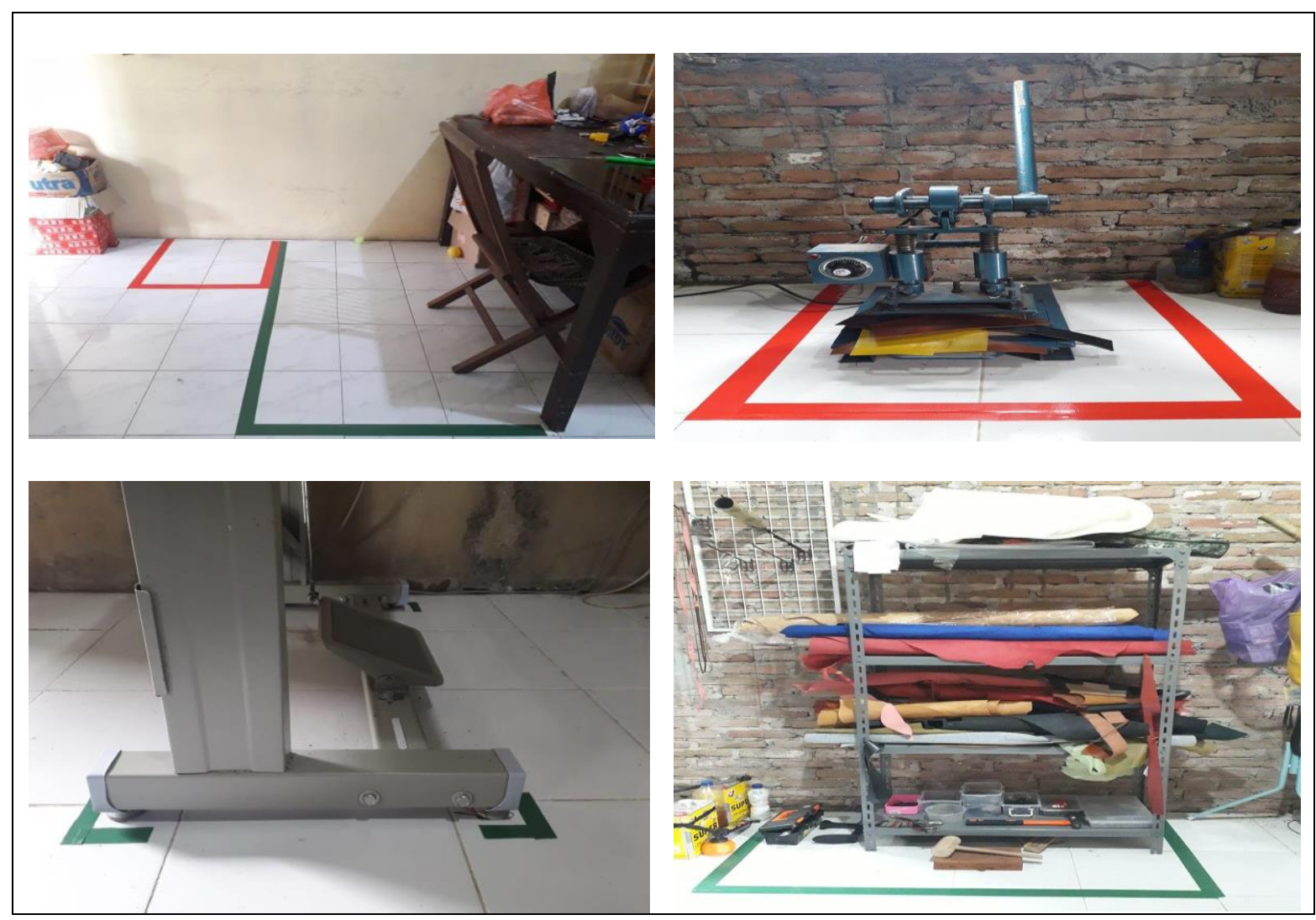

Gambar 6. Aktivitas Seiso (Resik)

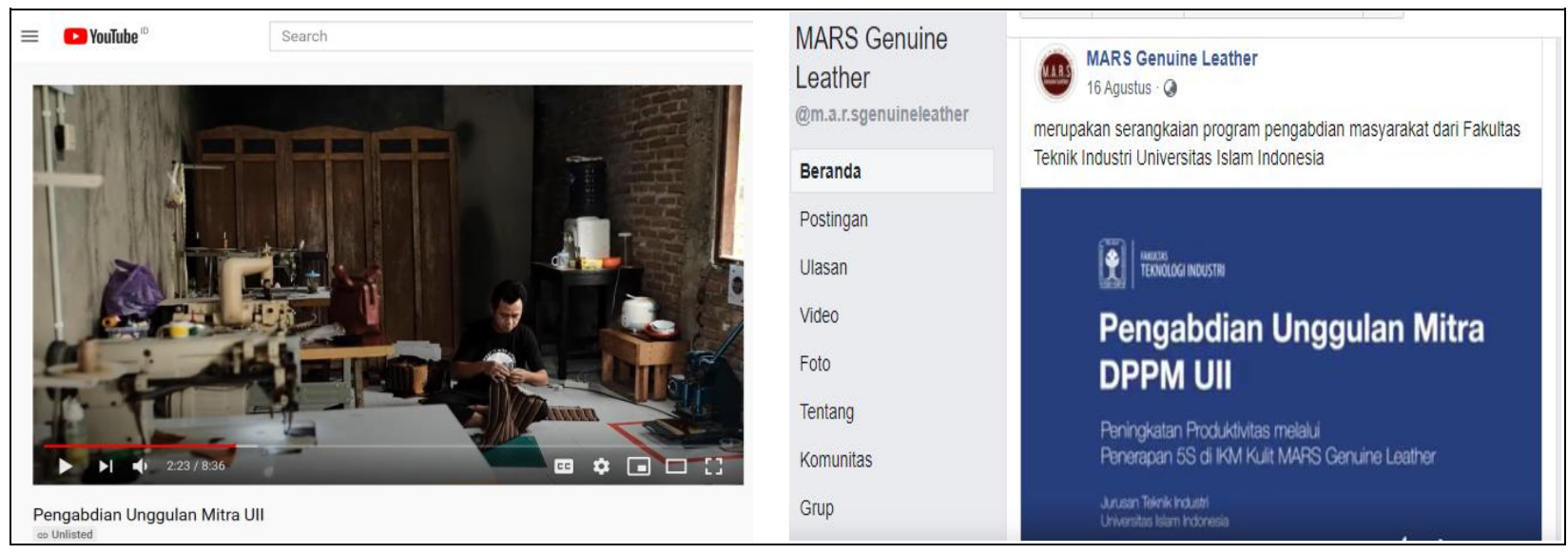

Gambar 7. Video Penerapan 3S Pertama di IKM MARS Genuine Leather 


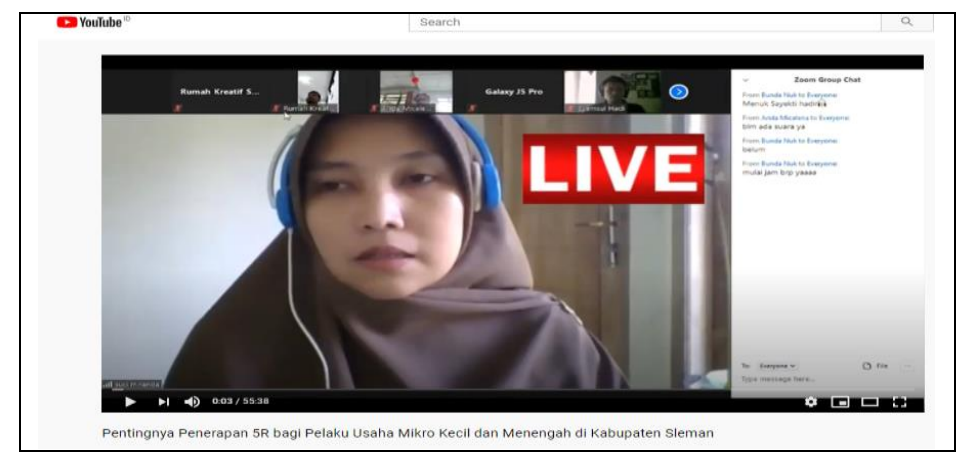

Gambar 8. Pelatihan Penerapan 5S di IKM oleh Disperindag Kabupaten Sleman

Tabel 2. Contoh Form Checklist

\section{CHECKLIST ACTIVITY}

\begin{tabular}{|c|c|c|c|c|c|}
\hline SEIRI & OK & SEITON & OK & SEISO & OK \\
\hline Persiapan Seiri & & Persiapan Seiton & & Persiapan Seiso & \\
\hline $\begin{array}{l}\text { Siapkan Tape warna } \\
\text { merah }\end{array}$ & & $\begin{array}{l}\text { Buang barang yang tidak } \\
\text { diperlukan }\end{array}$ & & Siapkan seluruh alat pembersihan & \\
\hline $\begin{array}{l}\text { Siapkan Kardus } \\
\text { kosong }\end{array}$ & & $\begin{array}{l}\text { Bersihkan bekas tempat } \\
\text { penyimpanan }\end{array}$ & & $\begin{array}{l}\text { Sesuaikan dengan karakteristik } \\
\text { kebutuhan area }\end{array}$ & \\
\hline
\end{tabular}

Melalui hibah pengabdian ini, pihak IKM MARS Genuine Leather telah mendapatkan pengalaman dan pendampingan implementasi 3S/3R secara langsung. Pada tahap Seiri (Ringkas), ternyata ditemukan sangat banyak barang-barang yang tidak dipakai seperti nota-nota kadaluarsa, sampah bungkus makanan, alat tulis rusak, dan sebagainya. Mereka tidak menyadari bahwa begitu banyak barang-barang yang tidak diperlukan telah disimpan dalam waktu yang cukup lama. Bersamaan dengan dilakukan kegiatan Seiri, pihak IKM sekaligus melakukan pembersihan seluruh area kerja. Tahap Seiton, semua barang yang telah teridentifikasi diberikan "rumahnya", label, dan garis pemisah. Hal ini membuat suasana kerja baik di area produksi maupun packaging menjadi lebih tertata rapi. Menurut pemilik dan karyawan, tiap barang dapat dengan mudah ditemukan dan dicari karena semua area kerja telah diberikan penunjukkan barang (dapat dilihat pada video). Sementara untuk S3-Seiso, alat kebersihan disediakan dan ditempatkan dengan baik sehingga dapat dengan mudah dicari dan dijangkau kapan saja oleh tiap orang khususnya saat ditemukan kotoran di sekitar area kerja.

Perlu diperhatikan bahwa penerapan 3S/3R yang berkelanjutan dan disiplin menjadi kunci sukses untuk mencapai level berikutnya, S4-Rawat (Seiketsu) dan S5-Rajin (Shitsuke). Menurut Kulkarni et al. (2016), kurangnya komitmen dari para anggota di suatu perusahaan menjadi penyebab utama kegagalan praktik 5S. Bagian dari komitmen para anggota adalah individualitas, norma dalam grup, komunikasi, kepaduan anggota, dan kepercayaan. Kurangnya komitmen dari level manajemen yang terdiri dari ketersediaan dana, pelatihan 5S, audit 5S, safety, dan infrastruktur 5S menjadi kegagalan kedua. Kegagalan 5S berikutnya disebabkan oleh stres dalam bekerja dimana dimensi pekerjaan, beban kerja, kontrol, dan budaya organisasi menjadi bagian dari stres tersebut. Penelitian lainnya juga menjelaskan beberapa tantangan yang dihadapi metode 5S yaitu tantangan budaya, tantangan filosofi, tantangan operasional dan implementasi, dan tantangan pengukuran (Ranjith Kumar et al., 2021).

Metode 5S/5R dapat meningkatkan efisiensi dalam pekerjaan sekaligus peningkatan produktivitas. Metode ini memastikan bahwa sistem tempat kerja berada pada keadaan teratur dan tertata. Karena 5S/5R adalah mengubah perilaku seseorang menjadi teratur dan disiplin, meletakkan tiap barang pada "rumahnya", maka pekerjaan akan menjadi lebih cepat, akan lebih ramping (lean). 
Ramping ini tidak hanya dari segi waktu, namun juga biaya. Oleh karena itu, pemilik dan karyawan IKM MARS harus bekerja bersama dengan penuh komitmen guna memastikan implementasi 3S/3R yang telah dilaksanakan dapat terus berkelanjutan demi tercapainya tujuan 5S/5R tersebut.

\subsection{Kendala Pelaksanaan Pengabdian Masyarakat}

Tantangan utama adalah kondisi masa pandemi COVID-19. Dikarenakan kondisi pandemi dimana diwajibkan physical dan social distancing, pelaksanaan kegiatan pengabdian masyarakat ini menjadi tidak mudah dan memiliki banyak kekurangan. Keterbatasan waktu pelaksanaan yang diizinkan oleh IKM adalah dari pukul 09.00 hingga 12.00 WIB. Karyawan yang bekerja juga dilakukan dengan metode shift sehingga penerapan tiap $\mathrm{S}$ tidak dapat dilaksanakan langsung pada waktu bersamaan. Sebagai contoh, penerapan Seiri (Ringkas) dan Seiton (Rapi) dilaksanakan di hari yang berbeda karena karyawan area packaging dan produksi bekerja di hari yang berbeda. Komunikasi menjadi kunci kelancaran pelaksanaan hibah pengabdian dimana tim harus rutin menanyakan kesediaan IKM untuk melanjutkan kegiatan pengabdian. Selain itu, Disperindag Sleman juga ikut memantau pelaksanaan kegiatan ini guna memastikan tim dan IKM tetap mengikuti peraturan Pemerintah sekaligus menerapkan protokol kesehatan dengan ketat. Dengan segala keterbatasan ruang gerak, tiap aktivitas pengabdian diusahakan untuk dapat diselesaikan meskipun waktu pelaksanaan lebih dari 6 bulan sesuai dengan kontrak hibah sebelumnya.

\section{Kesimpulan}

Tujuan dari pengabdian ini adalah memberikan pendampingan penerapan 3S pertama di IKM MARS Genuine Leather yaitu Seiri (Ringkas), Seiton (Rapi), dan Seiso (Resik). Pendampingan ini sebagai tindak lanjut dari hasil penelitian sebelumnya dimana nilai rantai pasok IKM MARS merupakan paling kecil diantara 6 IKM di Sleman. Selain itu, pembuatan video penerapan 3S di IKM MARS juga dapat digunakan sebagai pengetahuan bagi IKM lain sekaligus media promosi IKM MARS bahwa mereka telah menerapkan metode 5S untuk 3S pertama. Hasil pengabdian ini telah menginisiasi Dinas Perindustrian dan Perdagangan (Disperindag) Kabupaten Sleman untuk mengadakan pelatihan Kelas 5S bagi IKM dengan Suci Miranda sebagai pematerinya. Hasil lainnya adalah penelitian tentang $5 \mathrm{~S}$. Tim melanjutkan pengabdian ini menjadi 2 penelitian yang dilakukan oleh asisten (mahasiswa) dimana tim menjadi dosen pembimbing bagi kedua mahasiswa tersebut.

Untuk pengabdian selanjutnya, penerapan lanjutan Seiketsu (Rawat) dan Shitsuke (Rajin) dapat dilakukan. Sebelumnya, audit 3S sebaiknya dilaksanakan untuk menganalisis konsistensi penerapan 3S pertama. Hal ini dikarenakan tahap Seiketsu tidak dapat tercapai jika 3S pertama tidak dilakukan secara berkelanjutan. Membuat papan 5S dapat menjadi alat visual yang membantu IKM dalam mengevaluasi penerapan metode tersebut. Hasil pengabdian dapat dilanjutkan kepada penelitian seperti menganalisis produktivitas dengan penerapan 5S di IKM, menganalisis risiko implementasi 5S di IKM, key success factors penerapan 5S di IKM, dan sebagainya.

\section{Ucapan Terima Kasih}

Kami mengucapkan terima kasih kepada semua pihak atas kesempatan hibah dan segala dukungan yang telah diberikan: Direktur DPPM UII, Bapak Dr. Eng. Hendra Setiawan, S.T., M.T.; Pemilik IKM MARS, Ibu Heni Sulistyawati; dan mahasiswa, M. Farras Raihan dan Ilham Naufal Masrur yang melanjutkan hibah dalam bentuk penelitian 5S.

\section{Daftar Pustaka}

Buesa, R. J. (2009). Adapting lean to histology laboratories. Annals of Diagnostic Pathology, 13(5), 322-333. https://doi.org/10.1016/j.anndiagpath.2009.06.005

Chourasia, R., \& Nema, A. (2016). Review on Implementation of 5S methodology in the Services Sector. International Research Journal of Engineering and Technology. www.irjet.net 
Kulkarni, S. D., Student, P., \& Professor, A. (2016). 78 Yogish Study and Analysis of the Factors Affecting Sustainability of 5S. In International Journal of Engineering Technology (Vol. 4, Issue 6). www.ijetmas.com

Mehra, S., \& Singh, B. (2015). Identification of Barriers Affecting Implementation of 5S. 8354(4), 619-624.

Neves, P., Silva, F. J. G., Ferreira, L. P., Pereira, T., Gouveia, A., \& Pimentel, C. (2018). Implementing Lean Tools in the Manufacturing Process of Trimmings Products. Procedia Manufacturing, 17, 696-704. https://doi.org/10.1016/j.promfg.2018.10.119

Radzali, M. A., Adzrie, M., Chai, F. O., Elcy, K., Joselyn, R. M., Mohd-Lair, N., \& Madlan, M. A. (2019). Implementation of 5S in Small and Medium Enterprises (SME). Journal of Advanced Research Design Journal Homepage, 61, 1-18. www.akademiabaru.com/ard.html

Rai, P. (2016). EFFECTIVENESS OF 5S IMPLEMENTATION ON ORGANIZATIONS PERFORMANCE. Undefined.

Ranjith Kumar, R., Ganesh, L. S., \& Rajendran, C. (2021). An entropy based approach to 5S maturity. Materials Today: Proceedings, xxxx. https://doi.org/10.1016/j.matpr.2021.03.048

Sahoo, S., \& Yadav, S. (2018). Lean implementation in small- and medium-sized enterprises: An empirical study of Indian manufacturing firms. Benchmarking, 25(4), 1121-1147. https://doi.org/10.1108/BIJ-02-2017-0033

Tayal, A., \& Singh Kalsi, N. (2020). Review on effectiveness improvement by application of the lean tool in an industry. https://doi.org/10.1016/j.matpr.2020.11.431

Weigel, W. A. (2016). Redesigning an airway cart using lean methodology. Journal of Clinical Anesthesia, 33, 273-282. https://doi.org/10.1016/j.jclinane.2016.04.025 